\title{
Somatic Localization of a Specific Large-Conductance Calcium-Activated Potassium Channel Subtype Controls Compartmentalized Ethanol Sensitivity in the Nucleus Accumbens
}

\author{
Gilles Martin, Sylvie Puig, Andrzej Pietrzykowski, Paula Zadek, Patrick Emery, and Steven Treistman \\ Department of Neurobiology, University of Massachusetts Medical School, Worcester, Massachusetts 01605
}

\begin{abstract}
Alcohol is an addictive drug that targets a variety of ion channels and receptors. To address whether the effects of alcohol are compartment specific (soma vs dendrite), we examined the effects of ethanol (EtOH) on large-conductance calcium-activated potassium channels (BK) in cell bodies and dendrites of freshly isolated neurons from the rat nucleus accumbens (NAcc), a region known to be critical for the development of addiction. Compartment-specific drug action was indeed observed. Clinically relevant concentrations of EtOH increased somatic but not dendritic BK channel open probability. Electrophysiological single-channel recordings and pharmacological analysis of the BK channel in excised patches from each region indicated a number of differences, suggestive of a compartment-specific expression of the $\beta 4$ subunit of the BK channel, that might explain the differential alcohol sensitivity. These parameters included activation kinetics, calcium dependency, and toxin blockade. Reverse transcription-PCR showed that both BK channel $\beta 1$ and $\beta 4$ subunit mRNAs are found in the NAcc, although the signal for $\beta 1$ is significantly weaker. Immunohistochemistry revealed that $\beta 1$ subunits were found in both soma and dendrites, whereas $\beta 4$ appeared restricted to the soma. These findings suggest that the $\beta 4$ subunit may confer EtOH sensitivity to somatic BK channels, whereas the absence of $\beta 4$ in the dendrite results in insensitivity to the drug. Consistent with this idea, acute EtOH potentiated $\alpha \beta 4$ BK currents in transfected human embryonic kidney cells, whereas it failed to alter $\alpha \beta 1$ BK channel-mediated currents. Finally, an $\mathrm{EtOH}$ concentration $(50 \mathrm{~mm})$ that increased BK channel open probability strongly decreased the duration of somatic-generated action potential in NAcc neurons.
\end{abstract}

Key words: accumbens; alcohol; channel; dendrite; patch clamp; reverse transcription-PCR; RT-PCR

\section{Introduction}

Anatomical, behavioral, and electrophysiological studies have clearly identified the nucleus accumbens (NAcc) as a key region for the addictive properties of drugs of abuse, including alcohol. Although our knowledge of neuronal channels and receptors altered by alcohol has grown significantly, the mechanisms underlying alcohol-mediated modulation of synaptic integration remain poorly understood. Because synaptic integration takes place primarily in the dendritic arborization (for review, see Reyes, 2001), it is particularly important to determine whether the actions of drugs of abuse, such as alcohol on ion channels, differ between the dendritic and somatic compartments. This information has been difficult to obtain, because most electrophysiological studies that examine the effects of alcohol do not differentiate between signals elicited from the soma and the den-

Received Feb. 25, 2004; revised June 9, 2004; accepted June 9, 2004.

This research was supported by National Institutes of Health-National Institute on Alcohol Abuse and Alcoholism Grant 08003 (S.T.) and the Alcohol Beverage Medical Research Foundation (G.M.).

Correspondence should be addressed to Gilles Martin, Department of Neurobiology, University of Massachusetts Medical School, 55 Lake Avenue North, Worcester, MA 01655. E-mail: gilles.martin@umassmed.edu. DOI:10.1523/JNEUROSCI.0684-04.2004

Copyright $\odot 2004$ Society for Neuroscience $\quad$ 0270-6474/04/246563-10\$15.00/0 drites. In this study, we used excised inside-out patches that allow differential study of channels from each compartment.

Recent findings indicate that dendrite physiology varies from that of the soma. Properties of $\mathrm{Na}^{+}$and some $\mathrm{K}^{+}$channels were found to be different between soma and dendrites in a number of brain regions (Hoffman et al., 1997; Mickus et al., 1999; Martina et al., 2000; Williams and Stuart, 2000). Moreover, HaberstockDebic et al. (2003) recently reported that chronic morphine exposure induces the internalization of dendritic but not somatic $\mu$-opioid receptors in NAcc medium spiny neurons. We focused on BK channels because they are well known for shaping action potentials (Golding et al., 1999; Shao et al., 1999; Bennett et al., 2000; Pedarzani et al., 2000; Faber and Sah, 2002; Edgerton and Reinhart, 2003), which is a characteristic likely to be a key element coding the addictive properties of alcohol. In addition, they are very sensitive to intracellular calcium, making them well positioned to respond to modifications of the properties of the $\mathrm{Ca}^{2+}$-permeable NMDA receptor, an ionotropic receptor that is regarded as pivotal in synaptic plasticity in general (Malenka and Nicoll, 1993) and in drug addiction in particular (Trujillo and Akil, 1995). Moreover, BK channels are robustly potentiated by relevant concentrations of ethanol (Dopico et al., 1996; Chu et al., 1998; Knott et al., 2002; Crowley et al., 2003), although one study 
reported an inhibitory effect on neurons from dorsal root ganglia (Gruss et al., 2001). Finally, recent evidence obtained using Caenorhabditis elegans suggests that the BK channel is the sole mediator of intoxication in this worm model system (Davies et al., 2003).

BK channels exist as a complex of subunits, including the pore-forming $\alpha$ subunit and four regulatory $\beta$ subunits, which are the products of four distinct genes $(\beta 1-\beta 4)$. BK channels are characterized by their large conductance $(120-300 \mathrm{pS})$ and by their sensitivity to both voltage and intracellular $\mathrm{Ca}^{2+}$, properties that are modulated by $\beta$ subunits (Kaczorowski et al., 1996; Gribkoff et al., 1997; Vergara et al., 1998; Coetzee et al., 1999; Zagotta, 2001). The BK $\alpha$ subunit is ubiquitously expressed in the brain (Chang et al., 1997a). In contrast, among the $\beta$ subunits, only the $\beta 4$ subunit has been reported in the brain (Behrens et al., 2000; Brenner et al., 2000). Use of the inside-out patch-clamp approach enabled us to examine BK channel properties in distinct neuronal compartments. Our data are consistent with the interpretation that compartment-dependent ethanol (EtOH)induced potentiation of NAcc BK channel activity depends on the selective expression of the BK channel auxiliary subunit $\beta 4$ in the cell body.

\section{Materials and Methods}

Animals, slice preparation, and experimental solutions. We used young male Sprague Dawley rats $(80-150 \mathrm{gm})$ to prepare NAcc slices as described previously (Martin and Siggins, 2002). Briefly, after decapitation, the brains were rapidly transferred into a cold $\left(4^{\circ} \mathrm{C}\right)$, oxygenated, lowcalcium HEPES-buffered salt solution containing the following (in $\mathrm{mm}$ ): 234 sucrose, $2.5 \mathrm{KCl}, 2 \mathrm{NaH}_{2} \mathrm{PO}_{4}, 11$ glucose, $4 \mathrm{MgSO}_{4}, 2 \mathrm{CaCl}_{2}, 1.5$ HEPES. Slices were incubated for up to $6 \mathrm{hr}$ at room temperature (20$\left.22^{\circ} \mathrm{C}\right)$ in a gas $\left(95 \% \mathrm{O}_{2}\right.$ and $\left.5 \% \mathrm{CO}_{2}\right) \mathrm{NaHCO}_{3}$-buffered saline solution (in mM): $116.4 \mathrm{NaCl}, 1.8 \mathrm{CaCl}_{2}, 0.4 \mathrm{MgSO}_{4}, 5.36 \mathrm{KCl}, 0.89 \mathrm{NaH}_{2} \mathrm{PO}_{4}, 5.5$ glucose, $24 \mathrm{NaHCO}_{3}, 100$ glutathione, 1 nitro-arginine, 1 kynurenic acid, $\mathrm{pH} 7.35$, adjusted with $\mathrm{NaOH}(300-305 \mathrm{mOsm} / \mathrm{l})$. After $1 \mathrm{hr}$ of incubation, we dissected out the region of the nucleus accumbens with the aid of a dissecting microscope. We incubated the tissue for $25 \mathrm{~min}$ in an oxygenated $\left(100 \% \mathrm{O}_{2}\right.$ with constant stirring) HEPES-buffered solution in the inner chamber of a Cell-Stirr flask (Wheaton, Millville, NJ) containing papain $(1 \mathrm{mg} / \mathrm{ml})$ and the following (in $\mathrm{mm}$ ): $136 \mathrm{NaCl}, 0.44$ $\mathrm{KH}_{2} \mathrm{PO}_{4}, 2.2 \mathrm{KCl}, 0.35 \mathrm{NaH}_{2} \mathrm{PO}_{4}, 5.5$ glucose, 10 HEPES, 100 glutathione, 1 nitro-arginine, 1 kynurenic acid, and 1 pyruvic acid, $\mathrm{pH} 7.35$, with $\mathrm{NaOH}(300-305$ mOsm).

After mechanical trituration of the tissue using fire-polished Pasteur pipettes with successively smaller tip diameters, we plated the supernatant into a $35 \mathrm{~mm}$ Petri dish placed on the stage of the inverted microscope. The cells were allowed to attach to the dish for $10 \mathrm{~min}$ before replacing the $\mathrm{Na}^{+}$-isethionate solution with normal external solution flowing at a rate of $1.5 \mathrm{ml} / \mathrm{min}$ and composed of the following (in $\mathrm{mm}$ ): $142 \mathrm{NaCl}, 2 \mathrm{KCl}, 1 \mathrm{CaCl}_{2}, 23$ glucose, 15 HEPES, 10 glucose, $\mathrm{pH}$ 7.35, with $\mathrm{NaOH}$ (osmolarity, $300 \mathrm{mOsm} / \mathrm{l}$ ).

Bathing solutions. Throughout the experiment, a modified "background" $\mathrm{PO}_{4}$-free Hank's solution (in mM: $120 \mathrm{NaCl}, 10 \mathrm{KCl}, 2 \mathrm{MgCl}_{2}$, $2.2 \mathrm{CaCl}_{2}, 5$ glucose, 10 HEPES) was perfused through the recording dish. Excised membrane patches were exposed to (in mM) 135-140 K-gluconate, $0-4 \mathrm{~N}$-(2-hydroxyethyl)ethylenediamine- $N, N^{\prime}, N^{\prime}$-triacetic acid (HEDTA), 0-4 EGTA, 15 HEPES, $1 \mathrm{MgCl}_{2}$, and 0.5-2.2 $\mathrm{CaCl}_{2}$. $\mathrm{CaCl}_{2}, \mathrm{EGTA}$, and HEDTA concentrations were adjusted to obtain the desired concentrations of free calcium, ranging from 1 to $25 \mu \mathrm{M}$. Free$\mathrm{Ca}^{2+}$ concentrations were determined by the Sliders software program. These solutions were contained in $50 \mathrm{ml}$ syringes and expelled from hematocrit tubes. Pipette tips were positioned in the "mouth" of the hematocrit tube to prevent contamination from solution potentially leaking from nearby tubes. Drugs were applied either on the intracellular face of the membrane $(\mathrm{EtOH})$ or into the recording pipette solution [charibdotoxin (ChTx)].

Electrophysiological recordings. We used the standard single-cell inside- out patch-clamp recording method (Hamill et al., 1981). Briefly, we pulled and fire-polished patch electrodes from borosilicate capillary glass (Drummond, Broomall, PA) on a Brown-Flaming puller (Sutter Instruments, Novato, CA) to a final resistance of 3-4 $\mathrm{M} \Omega$ for somatic and 7-10 $\mathrm{M} \Omega$ for dendritic patches. The recording pipette solution contained the following (in mM): $145 \mathrm{~K}$-gluconate, $1 \mathrm{MgCl}_{2}, 2.2 \mathrm{CaCl}_{2}, 15 \mathrm{HEPES}, 4$ EGTA, 4 HEDTA, and 4-AP (10 mM) to block possible contaminating fast transient $I_{\mathrm{A}}$ currents. The capillaries were first filled through the tip and then backfilled with the recording solution. We recorded in voltageclamp mode with an Axopatch 200B amplifier and a DAC (digital analog converter) TL-1 interface from Axon Instruments (Union City, CA). BK channel currents were recorded at a sampling rate of $5 \mathrm{kHz}$ and low-pass filtered at $1 \mathrm{kHz}$ with an eight-pole Bessel filter. Potentials and currents were digitized, curve-fit, measured, stored, and plotted using the pClamp6 suite of acquisition and analysis software. When currents were evoked using a step protocol, leak currents were subtracted on-line. Action potentials were recorded in current-clamp mode using an EPC10 double amplifier and Patchmaster acquisition and analysis software (Heka Elektronik, Lambrecht/Pfalz, Germany). The recording pipette contained the following (in $\mathrm{mm}$ ): $145 \mathrm{~K}$-gluconate, $1 \mathrm{MgCl}_{2}, 0.5 \mathrm{CaCl}_{2}$, 15 HEPES, 1.5 HEDTA, 2 Na-ATP.

Open probability analysis and calcium sensitivity. The product of the total number of functional channels present in the membrane patch $(N)$ and the probability that a particular channel is open under steady-state conditions $\left(P_{\mathrm{o}}\right)$ was used as an index of channel activity. $N P_{\mathrm{o}}$ values were calculated from all-points amplitude histograms. In multiple channel patches of unknown $N$, knowing $N P_{\mathrm{o}}$, and the number of openings $\left(X_{\mathrm{o}}\right)$ during the period of observation $(T)$ allowed calculation of the mean open time $\left(t_{\mathrm{o}}\right)$ from the relationship: $t_{\mathrm{o}}=N P_{\mathrm{o}} T / X_{\mathrm{o}} .(N) P_{\mathrm{o}}$ data as a function of voltage was fitted with a Boltzmann function of the following type: $P_{\mathrm{o}}=\left[1+\exp -K\left(V-V_{0.5}\right)\right]^{-1}$, where $K$ is the logarithmic potential sensitivity and $V_{0.5}$ is the potential at which $P_{\mathrm{o}}$ is half maximal. When the $(N) P_{\mathrm{o}}$-voltage relationship is fitted by the Boltzmann curve, a plot of $\operatorname{LnN} P_{\mathrm{o}}$ as a function of voltage is linear at low values of $P_{\mathrm{o}}$. In this plot, the reciprocal of the slope is the potential needed to produce an e-fold change in $(N) P_{\mathrm{o}}$, which is routinely used as a measure of the voltage dependence of gating of BK channels. Then, the effective valency (z) can be calculated from the following: $1 /$ slope $=R T / z F$, where $R, T$, and $F$ have their usual meanings defined in the Nernst equation.

$\mathrm{EtOH}$ application. Data were sampled for a period of $2 \mathrm{~min}$. As a control, we recorded BK channel activity for $30 \mathrm{sec}$ twice to ensure a stable baseline activity. Then, EtOH was applied and BK channel activity was recorded in successive blocks of $30 \mathrm{sec}$ for 2-3 min. Maximal EtOH effects during this period were used in the analysis, regardless of the time of exposure. Data were expressed as mean $\pm \mathrm{SE}$ (with the number of cells or patches in parentheses).

Dwell time analysis. In single-channel patches, durations of open times were measured with half-amplitude threshold analysis. A maximumlikelihood minimization routine was used to fit curves to the distribution of open times. Determination of the minimum number of terms for adequate fit was established using a standard $F$ statistic table (significance level, $p<0.01)$. The slope of the unitary current amplitude currentvoltage relationship yielded the unitary conductance $(\gamma)$. Values for $I$ were obtained from the Gaussian fit of all-points amplitude histograms by measuring the distance between the modes corresponding to the closed state and the first opening level. For all experiments, reported voltages correspond to the potential at the intracellular side the membrane.

Reverse transcription-PCR. RNAs were extracted from four nucleus accumbens punches or from a fragment of rat liver with the RNeasy Protect Mini extraction kit (Qiagen, Valencia, CA) according to the instructions of the manufacturer. After extraction, the RNAs were treated with $20 \mathrm{U}$ of DNase I for $15 \mathrm{~min}$ at $37^{\circ} \mathrm{C}$ to minimize the risk of genomic DNA contamination. The RNA was then purified again on an RNeasy mini-column. The Titan One Tube reverse transcription (RT)-PCR kit (Roche, Basel, Switzerland) was used according to the instructions of the manufacturer to detect the presence of KCNMA1, KCNMB1, and KCNMB4 RNAs. The following pairs of primers were used: KCNMA1, CGAAGCTGATGAGGCATGACC (5' primer) and CCGATGCTGTCATCAAAC- 
TGC (3' primer); KCNMB1, ATCAAGGACCAGGAAGAGCTG (5' primer) and CTACTTCTGAGCTGCCAAGAC (3' primer); KCNMB4, CCAGGTGTACGTGAAC-AACTC ( $5^{\prime}$ primer) and CATGGCTTCTGCCTTGACTGC ( $3^{\prime}$ primer). Expected amplification product sizes are as follows: 531 bp for KCNMA1, 456 bp for KCNMB1, and 357 bp for KCNMB4. RNAs (200 ng) were used in each reaction. Before adding the enzyme mix, the RNAs and primers were denatured at $94^{\circ} \mathrm{C}$ for $3 \mathrm{~min}$. The reversetranscription reactions were then performed at $50^{\circ} \mathrm{C}$ for $30 \mathrm{~min}$, followed by 35 cycles of PCR amplification $\left(30 \mathrm{sec}\right.$ at $94^{\circ} \mathrm{C}, 30 \mathrm{sec}$ at $55^{\circ} \mathrm{C}, 1 \mathrm{~min}$ at $68^{\circ} \mathrm{C}$; after 10 cycles, $5 \mathrm{sec} /$ cycle were added to the elongation step). To verify that the signals detected were not caused by genomic DNA contamination, RTPCRs were also performed for each pair of primers after the reverse transcriptase was heat inactivated.

Immunohistochemistry. Male Spraque Dawley adult rats, $(22-40 \mathrm{~d}$ of age) were obtained from Taconic Farms (Germantown, NY) and killed in accordance with the National Institutes of Health guidelines on the care and use of animal study protocol approved by the University of Massachusetts Animal Care and Use Committee. Brain fragments containing NAcc were rapidly removed from the skull, fixed overnight in $4 \%$ paraformaldehyde in PBS, and immersed in 20\% sucrose/PBS for at least 24 hr. After placing into sucrose, tissue was briefly washed in PBS, embedded in $6 \%$ gelatin-egg yolk mixture in cardboard molds, and exposed to concentrated formaldehyde vapors for at least $3 \mathrm{~d}\left(4^{\circ} \mathrm{C}\right)$. After hardening, $40 \mu \mathrm{m}$ sections were cut on a freezing microtome, and sections were placed in net-well carriers (one section per carrier). The floating sections were permeabilized/blocked in the buffer containing $10 \%$ NGS, $0.1 \%$ BSA, $0.4 \%$ Triton X-100 in PBS/0.02\% sodium azide, $\mathrm{pH} 7.4$, for $1 \mathrm{hr}$ at room temperature. Sections were incubated (overnight at $4^{\circ} \mathrm{C}$ ) with specific polyclonal primary antibodies (1:300) against BK channel subunits $[\alpha, \beta 1$ (Affinity BioReagents, Golden, CO) and $\beta 4$ (gifts from Millennium Pharmaceuticals, Cambridge, MA)], rinsed, and incubated for $1 \mathrm{hr}$ at room temperature with Alexa 594-tagged, anti-rabbit secondary antibody (1:400; Molecular Probes, Eugene, OR). Next, sections were incubated with neuronal-specific nuclear protein (Chemicon, Temecula CA; overnight at $4^{\circ} \mathrm{C}$ ), a mature neuron marker, rinsed, and incubated for 1 $\mathrm{hr}$ at room temperature with Alexa 488-tagged anti-mouse secondary antibody (1:400; Molecular Probes). To probe the presence of BK channel subunits in astrocytes, sections were costained with monoclonal antibody against GFAP (1:200; Chemicon) and Alexa 488-tagged, antimouse secondary antibody. Sections were rinsed in PBS, mounted on SuperFrost Plus microslides (VWR Scientific, Batavia, IL) in Prolong Antifade medium (Molecular Probes), and stored at $4^{\circ} \mathrm{C}$.

Image acquisition and quantification. Fluorescence images were acquired with a fluorescent microscope using a Nikon (Tokyo, Japan) $40 \times$ objective. Adobe Photoshop software (Adobe Systems, San Jose, CA) was used to quantify the number of cells. A total of 30 images per antibody (against $\alpha, \beta 1$, and $\beta 4$ ) from three independent experiments was chosen randomly for cell quantification. Quantification was done using Hoechst dye to determine the total number of cells and using a specific antibody against each BK channel subunit to calculate the number of cells containing each subunit. Samples of similar size (number of pixels) were used in each count, and cells were chosen according to their neuronal morphology (round shape, light staining). To estimate the relative proportion of $\beta 1$ versus $\beta 4$, a plot of fluorescence intensity versus exposure time was created for $\beta 1$ and $\beta 4$, and the area under each curve was measured.

Cell culture and expression of cloned human $\mathrm{K}_{c a}$ channels in human embryonic kidney 293 cells. All cell lines used were derived from human embryonic kidney (HEK) 293 cells and were a gift from Peter Ahring (Neurosearch A/S, Ballerup, Denmark). The cells were grown in DMEM supplemented with $10 \%$ fetal bovine serum, $50 \mathrm{U} / \mathrm{ml}$ penicillin, 50 $\mathrm{mg} / \mathrm{ml}$ streptomycin, and $2.5 \mathrm{~mm}$ HEPES (Invitrogen, San Diego, CA) at $37^{\circ} \mathrm{C}$ in a humidified $5 \% \mathrm{CO}_{2} / 95 \%$ air incubator. We used cell lines stably expressing hSlo $\alpha(\mathrm{HEK} / \alpha-1.2)$ and hSlo $\alpha \beta_{1}(\mathrm{HEK} / \alpha \beta-\mathrm{B} 7)$ or cell lines stably expressing hSlo $\alpha$ and transiently expressing $\beta_{4}$ ( $\beta_{4}$ expression construct kindly provided by Millenium Pharmaceuticals). For the transient expression of $\beta_{4} \mathrm{HEK} / \alpha-1.2$, cells were transfected with $4 \mu \mathrm{g}$ of expression plasmid ( $3 \mu \mathrm{g}$ of $\beta_{4}$ subunit DNA to $1 \mu \mathrm{g}$ of T cytotoxic/ suppressor lymphocyte antigen CD8 DNA) using Polyfect transfection reagent (Qiagen, Hilden, Germany) according to the instructions of the manufacturer. The transfected cells were plated onto $35 \mathrm{~mm}$ culture dishes $24 \mathrm{hr}$ after transfection and incubated for an additional $24-48 \mathrm{hr}$ to obtain maximal expression levels for electrophysiological recordings. Immediately before recording, each $35 \mathrm{~mm}$ culture dish was washed and incubated for $1 \mathrm{hr}$ in $2 \mathrm{ml}$ of high calcium bath solution containing $2 \mu \mathrm{l}$ of Dynabeads CD8 (Dynal, Oslo, Norway) as a marker for the transfected cells. Only cells with beads attached were used for electrophysiological recordings. Electrophysiological recording conditions were the same as for isolated NAcc neurons except that single-channel currents were recorded using an EPC-7 (List Electronics, Darmstadt, Germany) patch-clamp amplifier and sampled at $200 \mathrm{kHz}$ using pClamp 8 (Axon Instruments). Solutions were perfused using a rapid solution changer (RSC-200; Bio-Logic, Claix, France) connected to an EVH-9 system (Electrovalve; Molecular Kinetics, Pullman, WA).

\section{Results}

The present work addresses the role of compartmentalization on the acute effects of EtOH. We focused our attention on the largeconductance voltage- and calcium-dependent potassium channel BK, a channel that had never been described before in the NAcc region. We report that somatic BK channel open probability was strongly potentiated by EtOH in a dose-dependent manner, whereas dendritic BK channels showed much less sensitivity to EtOH. A combination of electrophysiological, molecular biological, and immunohistochemical approaches established the presence of the BK $\beta 4$ in the cell body and absence in the dendrite, consistent with a role of the $\beta 4$ subunit in compartmentspecific ethanol sensitivity.

\section{NAcc neurons express functional BK channels}

Although the presence of the BK channel $\alpha$ subunit has been reported in the striatal region (Behrens et al., 2000), the BK channel has not been identified in NAcc neurons. To assess BK channel $\alpha$ subunit expression, we used an antibody specifically directed against its pore-forming region. The specificity of this antibody was confirmed by evidence that it stained only HEK293 cells expressing the BK channel $\alpha$ subunit (Fig. $1 A, B$ ) but not untransfected cells (Fig. 1C,D). Using a specific neuronal marker (neuronal-specific nuclear protein) to label neurons specifically, we found that $\sim 90 \%$ of NAcc neurons express BK channels. This percentage was corroborated by whole-cell voltage-clamp data. After block of $I_{\mathrm{A}}$ and the delayed rectifier $\left(I_{\mathrm{DR}}\right)$ currents with 10 $\mathrm{mm} 4$-AP and $20 \mathrm{~mm}$ quinidine, respectively, 8 of 12 NAcc neurons had a TEA-sensitive outward current, whereas four did not (data not shown). Figure $1 E$ shows that the $\alpha$ subunit was not confined to the soma region but was visible on processes; the single arrowhead points to a primary dendrite and the double arrowhead points to what may be labeled secondary dendrites (Fig. $1 F)$.

The presence of functional BK channels in the membrane of medium spiny neurons was established by assessing their basic electrophysiological properties in inside-out patches. First, we examined voltage sensitivity by recording currents at various membrane potentials ranging from -100 to $+100 \mathrm{mV}$ while exposing the cytosolic face of the channels to $5 \mu \mathrm{M} \mathrm{Ca}^{2+}$. Figure $2 \mathrm{~A}$ shows the activity of a single $\mathrm{BK}$ channel recorded between -60 and $+20 \mathrm{mV}$. At $-60 \mathrm{mV}$, the channel opens sporadically $\left(P_{\mathrm{o}}=0.034\right)$. As the potential across the membrane is depolarized, the time spent in the open state increases steadily to reach an almost permanent open state at $+20 \mathrm{mV}\left(P_{\mathrm{o}}=0.95\right)$. We exposed the intracellular face of the same channel to $\mathrm{Ca}^{2+}$ ranging from 1 to $10 \mu \mathrm{M}$ while holding the membrane potential at -40 $\mathrm{mV}$ (Fig. $2 \mathrm{~B}$ ). As expected, BK channel activity was extremely low 

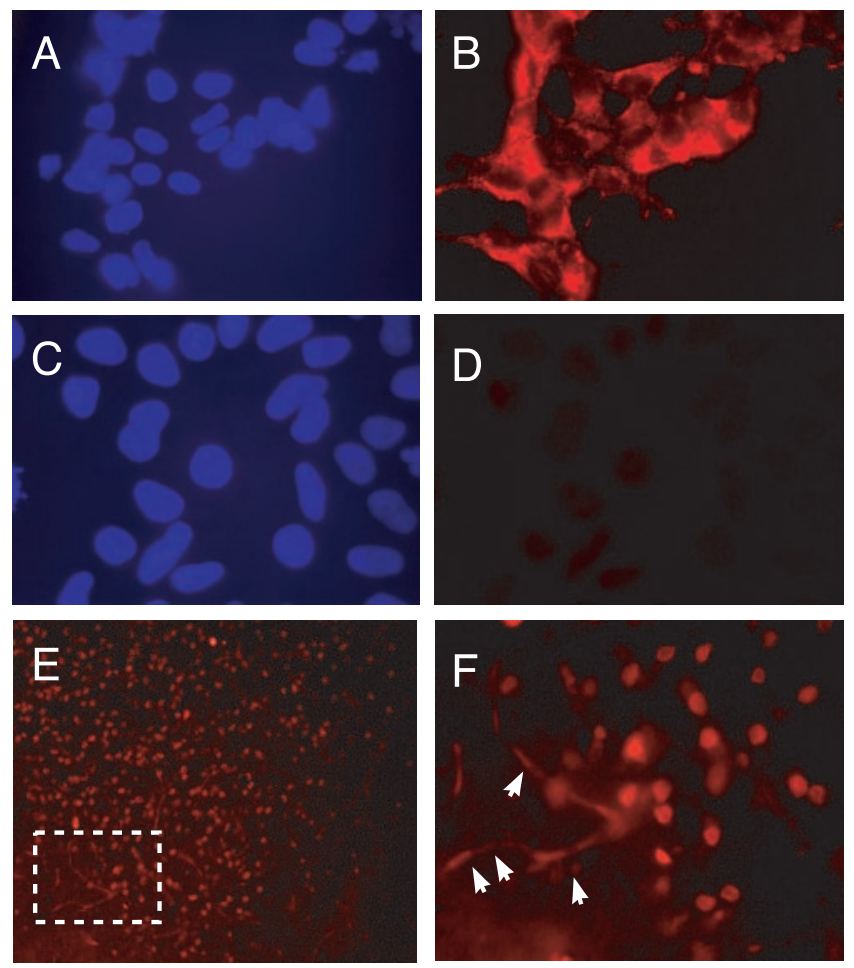

Figure 1. NAccneurons express $B K$ channel $\alpha$ subunits. $A$, Hoechst staining shows cell nuclei of BK channel $\alpha$ subunit in stably transfected HEK293 cells. B, The same neurons as in $A$ are stained with the BK channel $\alpha$ subunit, using a specific polyclonal antibody, visualized by fluorescence microscopy $(60 \times)$. C, Hoechst staining shows cell nuclei of untransfected HEK293 cells. D, BK channel $\alpha$ subunit antibody fails to stain untransfected HEK cells shown in C.E, Staining of $\alpha$ subunit in the core NAcc (10X; the anterior commissure is not shown). In the bottom left corner, the white box outlines a region shown at higher magnification $(40 \times)$ in $F$. $F$, Single and double arrowheads point to labeled primary and secondary processes, respectively, indicating that $\alpha$ subunits are not confined to the soma but are also expressed in neuronal processes.

$\left(P_{\mathrm{o}}=0.001\right)$ at $1 \mu \mathrm{M} \mathrm{Ca}{ }^{2+}$ but increased to $P_{\mathrm{o}}=0.24$ at $5 \mu \mathrm{M}$ before reaching an almost permanent open state at $10 \mu \mathrm{M} \mathrm{Ca}{ }^{2+}$ $\left(P_{\mathrm{o}}=0.89\right)$ (Fig. $\left.2 B\right)$. We plotted BK current amplitude of the patch shown in Figure $2 A$ as a function of membrane potential (Fig. $2 C$ ). As expected $\left([K]_{\mathrm{i}}=[K]_{0}\right)$, BK current reversed at $0 \mathrm{mV}$, and the current-voltage relationship was well fitted with a linear regression $(r=0.99)$, giving a slope conductance of $234 \mathrm{pS}$, in line with values reported for BK channels in brain and smooth muscle (for review, see McManus, 1991).

\section{EtOH potentiated somatic but not dendritic BK channels}

We examined the sensitivity of somatic BK channels to $50 \mathrm{mM}$ EtOH in inside-out patches in the presence of $5 \mu \mathrm{M} \mathrm{Ca}^{2+}$ (Fig. 3). In control conditions $\left(V_{\mathrm{h}}=-30 \mathrm{mV}\right)$, BK channels opened only briefly $\left(N P_{\mathrm{o}}=0.031\right)$. Within $1 \mathrm{~min}$ after exposure to $50 \mathrm{~mm}$ $\mathrm{EtOH}$, the activity of BK channels increased dramatically to reach an $N P_{\mathrm{o}}$ of 0.59 (Fig. $3 A$ ), returning to a level close to control after washout of the drug $\left(N P_{\mathrm{o}}=0.095\right)$. When averaged over eight patches, $50 \mathrm{~mm}$ EtOH increased somatic BK channel activity more than eightfold $(8.68 \pm 2.23)$ (Fig. 3C). Acute EtOHmediated enhancement of $\mathrm{BK}$ channel activity was concentration dependent between 1 and $50 \mathrm{~mm} \mathrm{EtOH}$ (Fig. 3C). Thus, 1, 10, and $25 \mathrm{~mm}$ EtOH increased BK channel activity in the soma $1.45 \pm$ 0.05 -fold, $2.5 \pm 0.78$-fold, and $4.05 \pm 1.57$-fold, respectively. However, the effects of EtOH were bimodal, and at the highest concentration tested $(100 \mathrm{~mm})$, EtOH increased BK channel
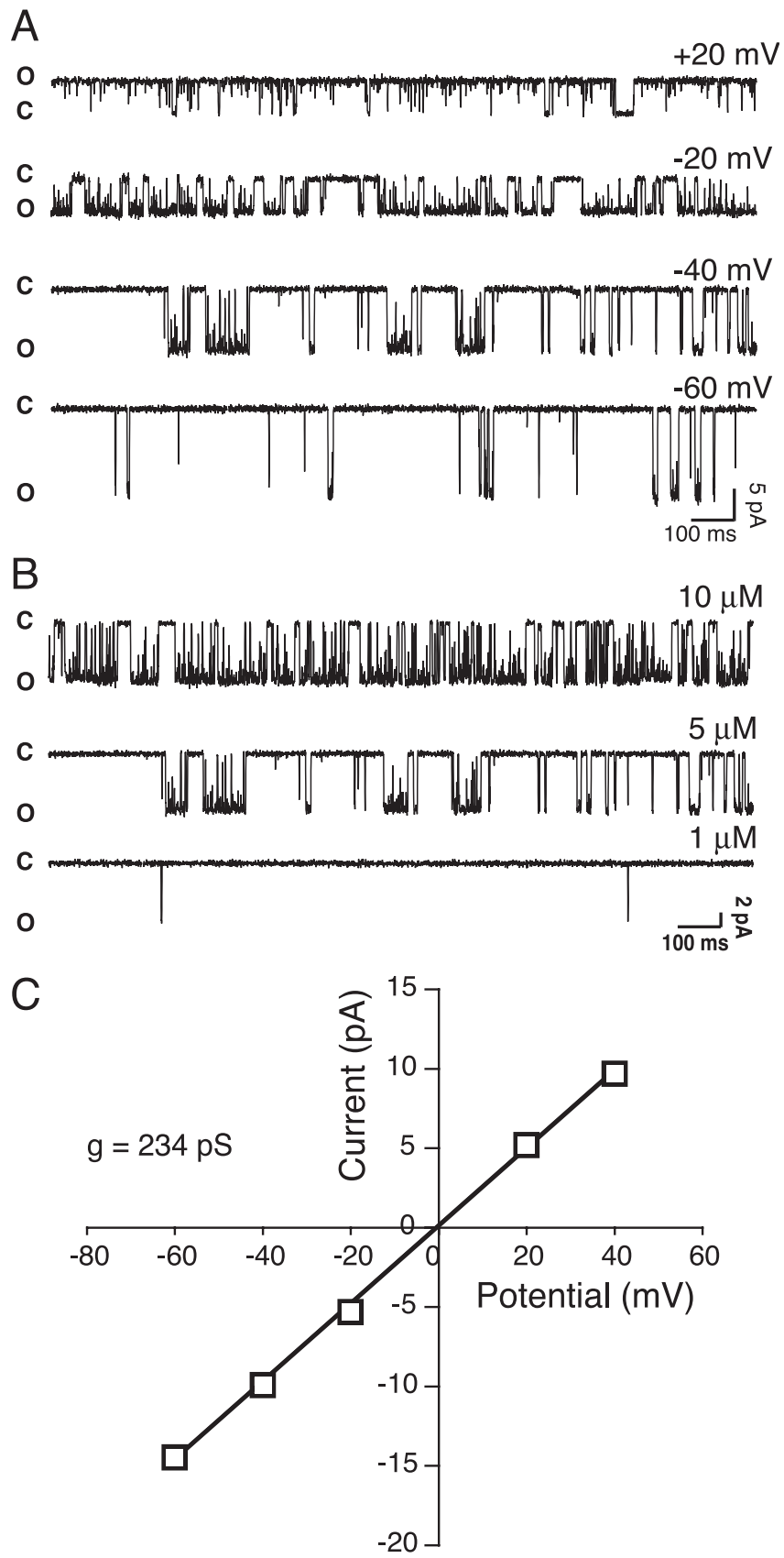

Figure 2. Voltage and calcium dependence of BK channels in NAccmedium spiny neurons. $A$, The time spent in the open state by a single somatic BK channel, recorded in inside-out patchclamp mode in the presence of $5 \mu \mathrm{m}$ free- $\mathrm{Ca}^{2+}$, increases as the membrane is depolarized. $B$, Traces recorded at $-40 \mathrm{mV}$ in the same channel as in $A$ show the dependence of channel activity on intracellular $\mathrm{Ca}^{2+}(1-10 \mu \mathrm{m})$. Although the channel is almost completely closed in low calcium, the time spent in the open state increases steadily with the increase of $\left[\mathrm{Ca}^{2+}\right]_{\mathrm{i}} \mathrm{C}$, Plot of BK channel current amplitude as a function of membrane potential. A linear fit of this relationship ( $r=0.99$ ) gave a BK channel unitary conductance of $234 \mathrm{pS}$. C and 0 represent the closed and open states, respectively.

open probability only $2.39 \pm 0.53$-fold, possibly indicating the presence of a lower-affinity inhibitory alcohol-binding site. Interestingly, we found significant variability in the effect of EtOH on somatic BK channels from patch to patch, at all EtOH concentrations tested. For example, potentiation by $50 \mathrm{~mm}$ EtOH ranged from 1.15-fold to 18.03-fold. Inhibition by the drug was never observed. Because we recorded only one patch per neuron, we cannot determine whether this variability exists within or be- 
A

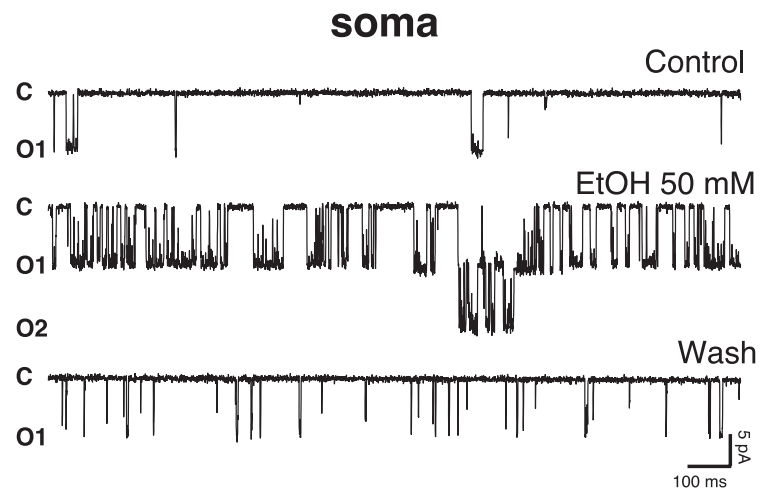

B

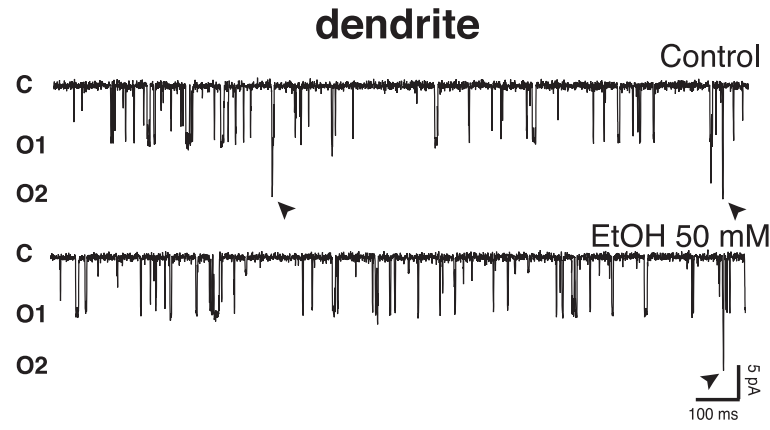

C

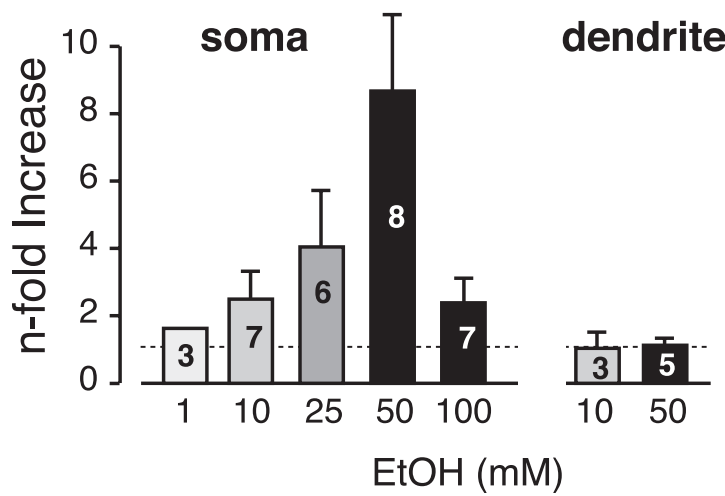

Figure 3. Acute EtOH increases somatic but fails to alter dendritic BK channel activity. $A$,

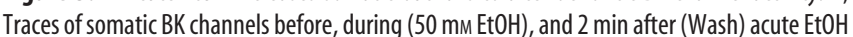
exposure $\left(V_{\mathrm{h}}=-30 \mathrm{mV} ; 5 \mu \mathrm{m} \mathrm{Ca}{ }^{2+}\right)$ in inside-out patches. EtOH strongly potentiated the activity of somatic BK channels. $B$ shows the lack of effects of $50 \mathrm{~mm}$ EtOH on dendritic BK channels recorded at $V_{\mathrm{h}}=-30 \mathrm{mV}$ in the presence of $5 \mu \mathrm{m} \mathrm{Ca}{ }^{2+}$ (wash not shown). The membrane patch was excised $25 \mu \mathrm{m}$ from the soma. Downward deflections indicate inward currents; C and 0 represent the closed and open states of the channels, respectively. C, Plot of averaged effects of various $\mathrm{EtOH}$ concentrations on somatic and dendritic BK channels. The dashed line indicates control level (onefold), and the numbers within bars represent the number of patches tested.

tween neurons. This result suggests a heterogeneous population of BK channels in this neuronal compartment.

We also examined the sensitivity of BK channels from proximal dendrites (10-40 $\mu \mathrm{m}$ from the soma). Figure $3 B$ shows the activity of two BK channels (arrowheads point to the sporadic simultaneous openings of the second channel) from a patch of membrane excised $30 \mu \mathrm{m}$ from the soma and recorded at -30 $\mathrm{mV}$. Activity was still unchanged $2 \mathrm{~min}$ after $50 \mathrm{~mm}$ EtOH exposure $\left(N P_{\mathrm{o}}=0.14\right)$. Thus, on average, 10 and $50 \mathrm{mM}$ EtOH did not affect (1.05 $\pm 0.3, n=3$, and $1.11 \pm 0.11, n=5$, respectively) (Fig. 3C) BK channel activity. In contrast to the soma, the effects of $\mathrm{EtOH}$ on dendritic BK channels were much more consistent across patches; EtOH failed to alter BK channel activity in any of the patches tested, suggesting a greater homogeneity of BK channel phenotype in this compartment. Given the striking difference in EtOH sensitivity between somatic and dendritic BK channels in NAcc medium spiny neurons, we explored the biophysical properties of the channel populations in the two compartments. Our results supported the presence of a more heterogeneous BK channel population in the soma, compared with that in the dendrite.

\section{Conductance}

The mean conductance of somatic BK channels was $251 \pm 7(n=$ $6), 227 \pm 11(n=13)$, and $216 \pm 6.9(n=9) \mathrm{pS}$ with 1,5 , and 10 $\mu \mathrm{M} \mathrm{Ca}^{2+}$, respectively. In dendrites, $\mathrm{BK}$ conductance at the same $\mathrm{Ca}^{2+}$ concentrations was $239 \pm 11(n=6), 217 \pm 9.4(n=9)$, and $213 \pm 5.6(n=7) \mathrm{pS}$. There were no statistically significant differences between soma and dendrite (Fig. $4 A$ ).

\section{Calcium dependence}

Figure $4 B$ shows the normalized open probability of individual patches as a function of membrane potential in the presence of 10 $\mu \mathrm{M} \mathrm{Ca}{ }^{2+}$. The potentials at which BK channels were open half of the time $\left(V_{0.5}\right)$ showed a wider range in the soma (from -38 to $+17 \mathrm{mV}$ ) than in the dendrites $(-35$ to $-20 \mathrm{mV})$, resulting from the presence of a population of channels from somatic membrane exhibiting a $V_{0.5}$ more depolarized than those observed in the dendrites. Figure $4 C$ shows the normalized $N P_{\mathrm{o}}$ of $\mathrm{BK}$ channels from soma (filled symbols) and dendrites (open symbols) as a function of the membrane potential. The $N P_{\mathrm{o}}-$ voltage relationship could be well fitted using the Boltzmann equation. The graph shows that $\mathrm{BK}$ channel open probability increases as the membrane is depolarized for all $\left[\mathrm{Ca}^{2+}\right]$ tested. The lesser $\mathrm{Ca}^{2+}$ sensitivity of somatic BK channels is demonstrated by a shift to the right, showing that at a given $\left[\mathrm{Ca}^{2+}\right]$, the membrane potential needs to be more depolarized to induce a similar open probability. The different $\mathrm{Ca}^{2+}$ sensitivities of somatic and dendritic BK channels are further illustrated in Figure $4 D$, where the $V_{0.5}$, the potential needed to induce an open probability of 0.5 , obtained from the Boltzmann fits, is plotted as a function of $\mathrm{Ca}^{2+}$ concentration. Thus, at $5 \mu \mathrm{M} \mathrm{Ca}^{2+}, V_{0.5}$ values were $-6.25 \pm 2.47$ and $+5.59 \pm 3.68 \mathrm{mV}$ for dendrite and soma, respectively $(p=$ $0.035)$. A similar difference was found in the presence of $10 \mu \mathrm{M}$ $\mathrm{Ca}^{2+}$, with $V_{0.5}$ values of $-28.14 \pm 2.2$ and $-19.1 \pm 3.7 \mathrm{mV}$ $(p=0.038) . V_{0.5}$ values at $25 \mu \mathrm{M} \mathrm{Ca}^{2+}(-69.3 \pm 2.3$ and $-63.5 \pm 3.5 \mathrm{mV})$ were not statistically different $(p=0.4)$.

\section{Soma and dendrites differ in their BK channel kinetics and gating}

Although whole-cell patch clamp is usually used to study kinetic properties (activation, deactivation, and inactivation) of ion channels, we could not use this approach, because it would not have enabled us to independently examine BK properties in each compartment. To circumvent this problem, we compiled a cumulative current trace built from the summation of repetitively evoked single-channel sweeps. The resulting current trace resembles the classical macroscopic current recorded in whole-cell configuration. The membrane of an inside-out patch was stepped from a holding potential of 0 to +40 or $+50 \mathrm{mV} 100$ times. A typical example showing 9 of 100 consecutive traces from a somatic patch is shown in Figure $5 A$. In both soma and dendrites, we found two populations of BK currents, one for which the activation was best fitted with a single exponential $(\tau=23.9 \pm 3.6$ msec in the soma and $27.01 \mathrm{msec}$ in the dendrites) and the other 
best fitted with a double exponential $\left(\tau_{\text {fast }}\right.$ and $\tau_{\text {slow }}$ were $7.6 \pm 2.2$ and $27.9 \pm 4.64$ msec in the soma and $6.6 \pm 1.8$ and $33.8 \pm$ $5.77 \mathrm{msec}$ in the dendrites, respectively). A typical example of a somatic BK current with a single $\tau$ of $28.34 \mathrm{msec}$ is shown in Figure $5 B$, whereas $B K$ currents that were best fitted with a double exponential are shown in Figure 5, $C$ and $D$. The ratio of channel subtypes observed was strikingly different in the two compartments: in somata, BK channels in seven of nine patches were best fitted with the slower activation rate, whereas in dendrites, 10 of 11 patches contained channels showing fast activation (Fig. 5E). We interpret this data to mean that although each compartment can contain similar BK subtypes, they are not equivalently distributed.

\section{Soma and dendrites differ in their BK open times}

The mean open time of BK channels from the soma and dendrites was measured while holding the potential at a value that produced an $N P_{\mathrm{o}}$ of 0.5 . In soma, and to a lesser extent in dendrites, the BK channel mean open time showed calcium dependency. Thus, in the soma, mean open time decreased from $6.55 \pm 1.01(n=10)$ to $2.44 \pm 0.39(n=6)$ msec between 1 and 10 $\mu \mathrm{M} \mathrm{Ca}{ }^{2+}$, respectively (Fig. $5 F$, Table 1 ). Interestingly, in the dendrites, the relationship between $\left[\mathrm{Ca}^{2+}\right]_{\mathrm{i}}$ and mean open time was reversed, and the mean open time increased from $4.47 \pm 0.42$ to $6.59 \pm 1.01 \mathrm{msec}$ for similar free- $\mathrm{Ca}^{2+}$ concentrations (Fig. $5 F$, Table 1 ).

The expression of $\beta 1$ and $\beta 4 \mathrm{BK}$ channel subunits in the NAcc is compartment specific

A potential explanation for the compartment-specific ethanol sensitivity of BK that is compatible with much of the biophysical and pharmacological characterization of the channel in each compartment involves a differential distribution of the BK $\beta 4$ subunit, with a greater representation in the cell body than in the dendrite. These data include the following: (1) $V_{0.5}$ values for $\beta 4$-containing channels would be expected to shift $V_{0.5}$ to more depolarized levels, as seen for a subpopulation in the soma; (2) activation rates were slower in the cell body, as would be expected for $\beta 4$-containing channels (Behrens et al., 2000; Brenner et al., 2000; Lippiat et al., 2003); (3) open times were markedly different in the two compartments, consistent with reports that mean open time is influenced by $\beta$ subunits (Nimigean and Magleby, 1999). Finally, 100 nM ChTX strongly inhibited dendritic BK channels in five of six patches (open probability decreased by $88 \pm 7 \%$ ), whereas in somata, ChTx inhibited BK activity by $82 \pm 11 \%$ in only 4 of 10 cases (data not shown), supporting the proposition that the toxin-resistant $\beta 4$-containing channels (Meera et al., 2000) were more common in the cell body.

RT-PCR confirmed the expression of three different BK subunits in the NAcc: KCNMA1 $(\alpha)$, KCNMB1 $(\beta 1)$, and KCNMB4 $(\beta 4)$. We did not examine the presence of transcripts coding for $\beta 2$ and $\beta 3$ subunits, because there are no sequences currently available for these subunits for the rat. In addition, we never observed inactivating BK currents that would be expected in BK channels containing $\beta 2$ and $\beta 3$ subunits.

As expected, we obtained a robust signal with primers for the pore-forming subunit KCNMA1. We also detected a robust signal with primers amplifying the KCNMB4 RNA, indicative of strong $\beta 4$ subunit expression in the NAcc (Fig. $6 A$ ). In addition, we observed a weaker signal with primers for KCNMB1 (Fig. 6A). These results support the notion that BK channels present in the NAcc contain $\alpha, \beta 1$, and $\beta 4$ subunits.

We could not rule out the possibility that the message coding for these BK channel subunits originated not from NAcc medium spiny neurons but rather from small blood vessels or astrocytes. $\beta 1$ subunits are reportedly very abundant in smooth muscle (Behrens et al., 2000; Weiger et al., 2000). However, a $\beta 1$-specific antibody clearly shows $\beta 1$ subunits on the membrane of both soma and dendrites of NAcc neurons (Fig. 6B). In contrast, the $\beta 4$ subunit is not observed in the dendrites of these neurons (Fig. $6 C)$. Finally, a specific astrocyte marker (GFAP) revealed that these cells were rare in the NAcc, where they are confined to the lower part of the wall of the ventricles, adjacent to the dorsal region of the NAcc core (Fig. 6D). Therefore, these cells cannot account for the intense labeling found throughout the NAcc. The number of $\beta 1$ - and $\beta 4$-labeled neurons as a proportion of the total number of neurons in several samples (Fig. $6 E$ ) indicated a predominance of $\beta 4$ subunit (53 $\pm 3 \%$ of neurons), compared with $27 \pm 2 \%$ labeled for $\beta 1$, suggesting that a fraction of NAcc neurons coexpressed $\beta 1$ and $\beta 4$ subunits. 
A Soma

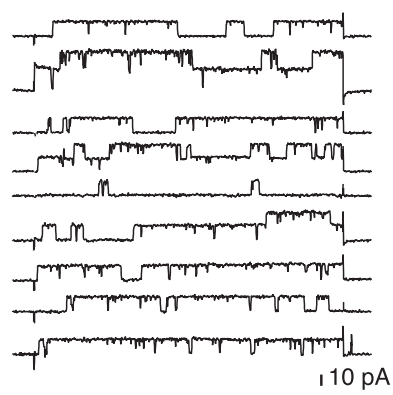

B
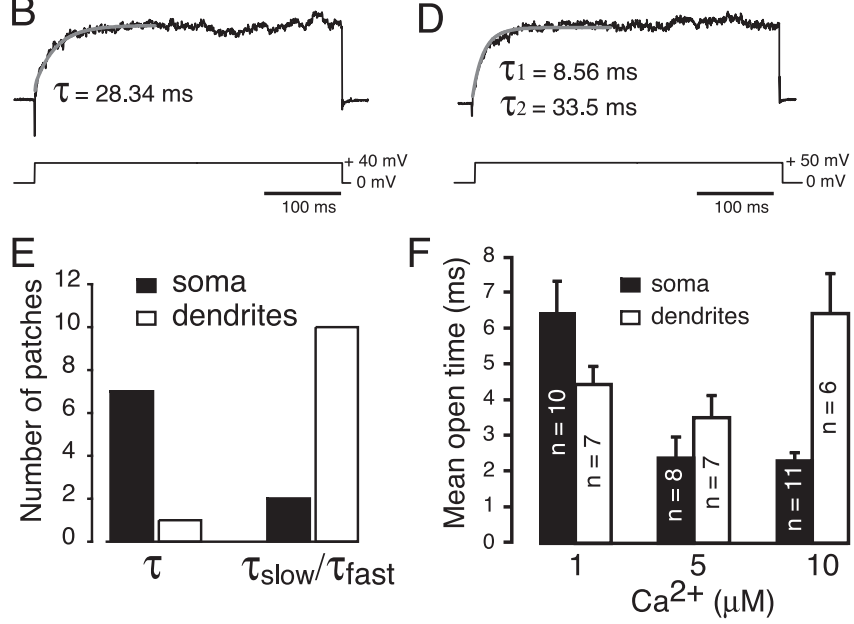

Figure 5. Gating properties of somatic and dendritic BK channels differ. $A$, A series of nine BK traces (leak-current subtracted) evoked by depolarizing a somatic membrane patch from 0 to $+40 \mathrm{mV}$. Channel activity was recorded in $5 \mu \mathrm{M} \mathrm{Ca}{ }^{2+}$ in an inside-out patch. $B$, Averaged current from 100 traces of the patch shown in $A$. BK current activation was best fitted with one exponential and gave a value of $\sim 28 \mathrm{msec}$. $C$, Nine consecutive dendritic BK currents recorded by depolarizing the membrane from 0 to $+50 \mathrm{mV}$. D, Averaged current from 100 traces of the patch shown in C. The dendritic BK current activation was best fitted with a double exponential ( $\tau_{\text {fast }}$ and $\tau_{\text {slow }}$ were 1.63 and $10.74 \mathrm{msec}$, respectively). E, Plot of the number of somatic (black columns) and dendritic (white columns) patches with an averaged current that was best fitted with a single $(\tau)$ or a double ( $\tau_{\text {slow }} / \tau_{\text {fast }}$ ) exponential. $F$, Histogram of the mean open time of somatic (filled bars) and dendritic (unfilled bars) BK channels measured at 1, 5, and $10 \mu \mathrm{M}$ $\mathrm{Ca}^{2+}$. The lack of tail currents in $B$ and $C$ is attributable to the potential after repolarization being set to $0 \mathrm{mV}\left(E_{\mathrm{K}}\right)$.

Table 1. The mean open time, expressed in milliseconds, of BK channels from NAcc soma and dendrites was measured in the presence of three different free-calcium concentrations

\begin{tabular}{llll}
\hline & $1 \mu \mathrm{M} \mathrm{Ca}^{2+}$ & $5 \mu \mathrm{M} \mathrm{Ca}$ & $10 \mu \mathrm{M} \mathrm{Ca}$ \\
\hline Soma & $6.55 \pm 1.01(n=10)$ & $2.37 \pm 0.73(n=7)$ & $2.44 \pm 0.39(n=6)$ \\
Dendrites & $4.47 \pm 0.42(n=7)$ & $3.8 \pm 0.56(n=7)$ & $6.59 \pm 1.1(n=6)$ \\
\hline
\end{tabular}

Numbers in parentheses indicate the number of patches tested in each experimental condition.

\section{Acute EtOH potentiates $\alpha \beta 4$ but not $\alpha \beta 1$ BK channels in HEK cells}

Our data suggest that the differential effects of EtOH on somatic versus dendritic BK channels reflect the selective expression of the $\beta 4$ subunit in the soma. To test the validity of this interpretation, we transfected human BK channel message encoding the $\alpha$ subunit with either $\beta 1$ or $\beta 4$ subunit into HEK293 cells and tested the acute effects of 25 and $50 \mathrm{~mm} \mathrm{EtOH}$. We found that neither concentration of EtOH affected $\alpha \beta 1$ BK channel open probability (Fig. 7). In contrast, EtOH increased the open prob-
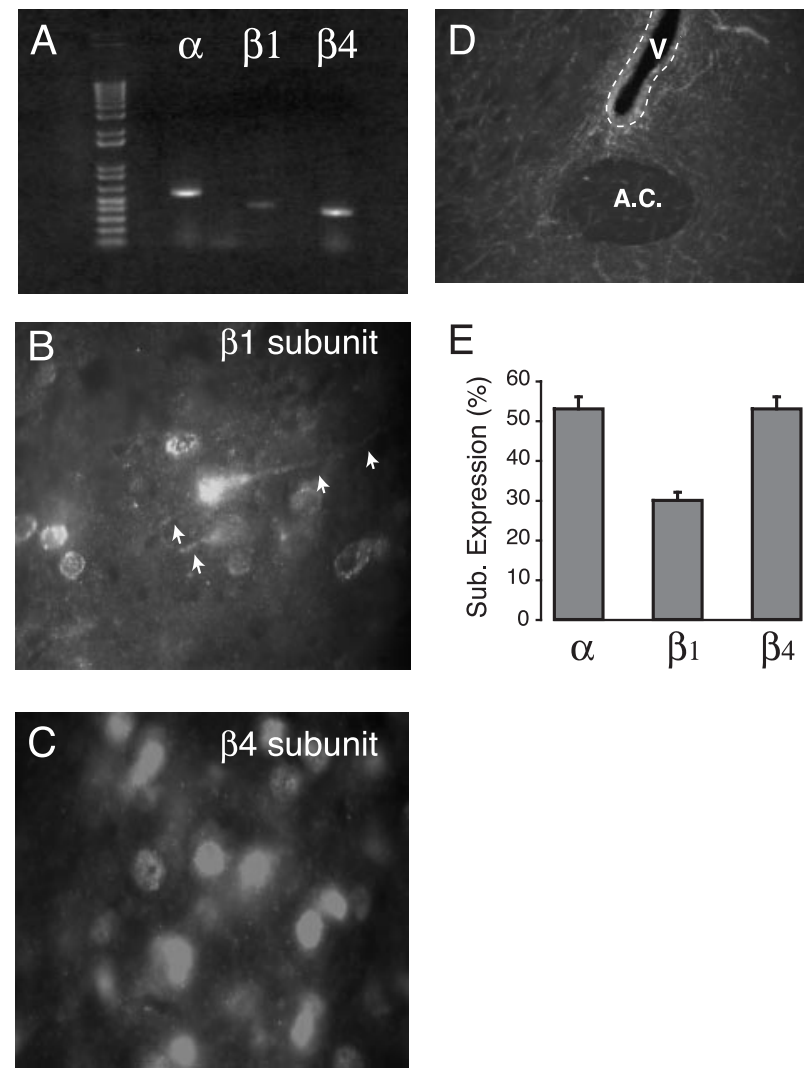

Figure 6. BK channel subunit expression in the NAcc. $A, R T-P C R$ was used to detect mRNA for KCNMA1 (lane 1-2), KCNMB1 (lane 3-4), and KCNMB4 (lane 5-6). The amplification product (lanes 2, 4, 6) has the expected size. No amplification product was observed when the reverse transcriptase was heat inactivated, demonstrating that the amplification products are originating from RNA and not from genomic DNA. As an additional control, we also used liver mRNA, where BK channels are not expected to be found. No amplification product was detected in this organ (data not shown). Molecular ladder (in kilobases): $0.1,0.2,0.3,0.4,0.5,0.65,0.85,1$, $1.65,2,3,4,5,6,7,8,9,10,11,12$. Lines are not numbered; two ladders are used. $B$, Immunohistochemistry using BK $\beta 1$-specific antibody revealed the presence of this subunit in somatic and dendritic compartments. The arrows show labeled processes. C, A $\beta 4$-specific antibody indicates that expression of this subunit was limited to cell bodies. D, Immunohistochemical determination of the presence of BK subunits in astrocytes. Antibody against astrocyte marker (GFAP) revealed that astrocytes are rare and confined to the lower part of the wall of the ventricles (V) delineated by a white dashed line, adjacent to the dorsal region of the NAcc core, ruling out a contribution of these cells to the BK labeling found throughout the NAcc region. The large dark mass is the anterior commissure (A.C.). E, Quantification of cells expressing each BK subunit shows that $\sim 50 \%$ of neurons in NAcc contain $\alpha$ and $\beta 4$ subunits and only $\sim 30 \% \beta 1$ subunits.

ability of $\alpha \beta 4$ BK channels in a dose-dependent manner (Fig. 7). Thus, $25 \mathrm{~mm}$ EtOH increased BK channel open probability almost twofold $(1.85 \pm 0.25 ; n=4)$, whereas the effect of $50 \mathrm{~mm}$ EtOH was almost fourfold $(3.7 \pm 0.81 ; n=5)$. These data suggest that the sensitivity of somatic BK channels is likely associated with the expression of $\beta 4$, whereas its insensitivity in the dendrites might be explained by the predominant expression of the $\beta 1$ subunit and the relative absence of the $\beta 4$ subunit.

\section{EtOH modulates NAcc action potentials}

We examined the physiological consequences of EtOH by determining the effects of the drug on NAcc action potentials recorded in current clamp. We found that $50 \mathrm{~mm} \mathrm{EtOH}$ strongly accelerated the repolarization phase of action potentials (APs) (Fig. 7B) $(n=3)$, which is in agreement with its excitatory effect on BK channel open probability. 


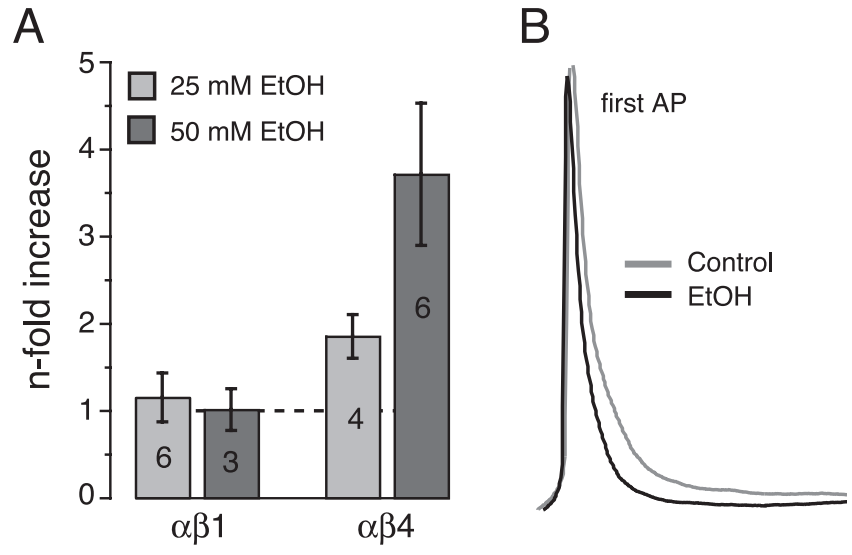

Figure 7. $\quad A$, Effects of 25 and $50 \mathrm{~mm}$ EtOH on $\alpha \beta 1$ and $\alpha \beta 4$ channels expressed in HEK293 cells. The graph shows the mean EtOH-mediated potentiation of open probability recorded in the presence of $5 \mu \mathrm{M} \mathrm{Ca}{ }^{2+}$. Although 25 and $50 \mathrm{~mm}$ EtOH fail to alter $P_{0}$ of $\alpha \beta 1$ BK channels, $\alpha \beta 4$ channels show a concentration-dependent potentiation of BK channel activity by the drug. The dashed line shows the baseline activity of $B K$ channels in control conditions before $\mathrm{EtOH}$ exposure. B, EtOH $(50 \mathrm{~mm})$ accelerates the repolarization of NAcc action potential (dark trace) compared with control (light trace). Action potentials were evoked by injecting $10 \mathrm{pA}$ positive current under current-clamp conditions.

\section{Discussion}

The data presented in this study demonstrate: (1) the expression of functional BK channels on the membrane of soma and dendrites of nucleus accumbens medium spiny neurons; (2) the concentration-dependent potentiation by EtOH of somatic, but not dendritic, BK channel open probability; (3) cell body-specific expression of the $\mathrm{BK}$ channel $\beta 4$ subunit, possibly underlying the selective sensitivity of BK channels to $\mathrm{EtOH}$; and (4) potentiation of $\beta 4$-containing, but not $\beta 1$-containing, BK channels expressed in HEK293 cells.

\section{Expression of BK channels in the NAcc}

Our electrophysiological and anatomical results reveal the expression of BK channels in NAcc medium spiny neurons. In the adult rat brain, Knaus et al. (1996) and Chang et al. (1997a) showed that BK $\alpha$ subunit mRNA is found in the neocortices and olfactory cortices, hippocampus, cerebellum, striatum, thalamus, and amygdala, corroborating a number of electrophysiological studies (Bielefeldt et al., 1992; Dopico et al., 1996; Kang et al., 1996; Chavis et al., 1998; Hicks and Marrion, 1998; Martin et al., 2001; Faber and Sah, 2002; Edgerton and Reinhart, 2003). Among the four auxiliary subunits $(\beta 1-\beta 4)$ identified so far, $\beta 4$ has been found to be the predominant form in the brain (Behrens et al., 2000; Brenner et al., 2000; Weiger et al., 2000). Interestingly, approximately half of all NAcc neurons were labeled with the $\beta 4$ antibody, correlating with the percentage labeled for the $\alpha$ subunit, suggesting that these two subunits are coexpressed. Because there are also two major populations of cells in the NAcc, the enkephalin-containing and substance-P-containing neurons (for review, see Meredith, 1999), it is possible that the $\alpha / \beta 4$ complex may be specifically found in one or the other group.

The presence of the BK channel $\beta 1$ subunit in the NAcc was surprising, because it had been believed to be present exclusively in smooth muscles of peripheral organs (Behrens et al., 2000; Weiger et al., 2000). It is unlikely that our findings are artifactual for several reasons: (1) positive identification was made for both mRNA, using RT-PCR, and for protein, using antibody; (2) a highly selective antibody commonly used against $\beta 1$ subunit clearly showed that the staining originated from NAcc neurons;
(3) the same immunostaining also revealed strong $\beta 1$ subunit staining in magnocellular neurons of the supraoptic nucleus (data not shown), whereas none of the surrounding brain regions were stained, clearly demonstrating the specificity of the antibody used in our study; and (4) only $\sim 25 \%$ of all medium spiny neurons were labeled, an unlikely result assuming a nonspecific $\beta 1$ antibody.

\section{EtOH effects on BK channels and its compartmentalization}

With the exception of one study, which reported an inhibition (Walters et al., 2000), the potentiation of BK channel activity by acute alcohol has been documented in a number of preparations such as the brain (Dopico et al., 1996), growth hormone 3 pituitary clonal cells (Jakab et al., 1997), and reconstituted planar lipid bilayers (Chu et al., 1998; Crowley et al., 2003). Our results in the NAcc demonstrate a potentiation of the open probability of somatic BK channels by relevant concentrations of EtOH, whereas dendritic channels were unaffected by similar concentrations. Compartment-specific effects of EtOH have been documented previously for hormone-releasing magnocellular neurons, in which BK channels in the cell bodies of SON are not affected by ethanol at relevant concentrations, whereas they are potentiated in terminals of the neurohypophysis (Dopico et al., 1999). This is the first report of a similar dichotomy between the somatic and dendritic compartments.

We suggest that the differences we observed in subunit composition between soma and dendrites in the NAcc could explain the differential effects of EtOH on BK channels. A correlation between subunit composition and ethanol sensitivity has been reported for other ion channels (for review of calcium channels, see Crews et al., 1996) and ionotropic receptors (e.g., GABA and NMDA). The NMDA receptor NR2B subunit is believed to favor EtOH-mediated inhibition of NMDA currents (Chu et al., 1995; Kalluri and Ticku, 1999; Peoples and Stewart, 2000), and splice variants of the NR1 subunit are similarly differentially sensitive to the drug (Koltchine et al., 1993). The enhancement of GABAmediated current by EtOH is thought to be mediated in part by its $\alpha 1$ subunit (Mihic et al., 1997). In the NAcc, the differential subcellular expression of $\beta 1$ and $\beta 4$ is confirmed by the immunohistochemistry and by their biophysical properties. Thus, BK channel slower activation rate and lower calcium dependency in the soma is in agreement with studies showing similar properties for $\alpha \beta 4$ BK channels in expression systems (Brenner et al., 2000; Lippiat et al., 2003). Our pharmacological results lead to a similar conclusion. Data from our laboratory showing that BK channels expressed in terminals of hypothalamic magnocellular neurons are sensitive to EtOH, unlike their somatic counterparts (Dopico et al., 1999), resemble the dichotomy found in the NAcc. Indeed, we recently found that the BK channel $\beta 4$ subunit is almost exclusively expressed in the terminals, whereas $\beta 1$ is found only in the soma of these neurons (in preparation), mirroring closely the present results of the effects of $\mathrm{EtOH}$ on BK channels from the soma and dendrites of NAcc medium spiny neurons. Finally, the fact that almost all dendritic BK channels, unlike somatic ones, are sensitive to ChTx further strengthens the idea that BK channels in the former compartment are composed of $\beta 1$ subunits rather than $\beta 4$-containing channels.

Although subunit composition is a likely candidate to explain the compartment-specific effects of EtOH on BK channels, a number of additional factors may contribute. These include differences in membrane lipid composition of soma and dendrites. The plasma membrane is a highly heterogeneous environment in which lipid domains exist that can serve important roles in cell function (Welti and Glaser, 1994; Bevers et al., 1999; London, 
2002). Thus, modification of the lipid environment can alter BK channel activity (Moczydlowski et al., 1985; Clarke et al., 2002) as well as the sensitivity of this channel to EtOH (Crowley et al., 2003). However, although it is known that lipid composition varies from region to region in the brain (Chavko et al., 1993), variability between dendrites and soma within the same neuron has not been reported to our knowledge. Other possibilities also must be considered, such as post-translational modulation of the BK channel by phosphorylation, which is known to affect the activity and alcohol pharmacology of the BK channel.

\section{Physiological consequences}

The physiological role of the BK channel has been extensively studied in a number of preparations. BK channels are activated by membrane depolarization and by an increase in intracellular calcium, as occurs during calcium influx through the voltage-gated calcium channels to which they are coupled (Marrion and Tavalin, 1998). BK channels play a role in controlling neurotransmitter release and also in modulating action potential shape and frequency at the somatic level (Shao et al., 1999). In the NAcc, we found that $50 \mathrm{~mm} \mathrm{EtOH}$ accelerated the repolarization of action potentials. Although we have not conclusively demonstrated that this effect is solely caused by actions on BK channels, the increase of BK channel open probability by EtOH strongly suggests that EtOH does alter the shape of medium spiny neuron APs. This likely modulates the pattern of action potentials sent to the terminals, influencing the release of GABA and the resulting integration within and beyond the NAcc.

Interestingly, Dopico et al. (1999) reported a similar finding in the hypothalamic-neurohypophysial $(\mathrm{NH})$ system, where BK channels in NH terminals that predominantly contain the $\alpha \beta 4$ channel (our unpublished observation) participate in shaping action potentials, whereas BK channels in the associated cell bodies within the hypothalamus, where the $\alpha \beta 1$ form of the channel predominates, do not participate in shaping the spike.

The lack of sensitivity of NAcc dendritic BK channels to acute EtOH might suggest that alcohol effects on NAcc neurons mediated through BK channels are circumscribed to the soma and have little impact on the integration of dendritic electrical activity. This last point is critical, because the vast majority of glutamate, GABA, and serotonin projections to the NAcc medium spiny neurons establish synaptic contact primarily on dendrites of these cells (for review, see Meredith, 1999). However, in addition to the role that BK channels in the NAcc cell body may play by their direct response to EtOH, dendritic BK channels may also play a role in the response to $\mathrm{EtOH}$, despite their lack of direct response. EtOH is likely to lower intracellular calcium levels by inhibiting NMDA receptors and voltage-gated calcium channels (Nie et al., 1994; Widmer et al., 1998), two heteromultimeric complexes colocalized with BK channels (Marrion and Tavalin, 1998; Isaacson and Murphy, 2001). These changes in dendritic calcium levels may be transduced by the associated BK channels, ultimately influencing input and output patterns of NAcc neurons. Thus, the presence of BK channels in NAcc neurons, as well as their differential sensitivity to ethanol, may play an important role in the response to ethanol in this important component of the reward pathway.

\section{References}

Behrens R, Nolting A, Reimann F, Schwarz M, Waldschutz R, Pongs O (2000) hKCNMB3 and hKCNMB4, cloning and characterization of two members of the large-conductance calcium-activated potassium channel beta subunit family. FEBS Lett 474:99-106.
Bennett BD, Callaway JC, Wilson CJ (2000) Intrinsic membrane properties underlying spontaneous tonic firing in neostriatal cholinergic interneurons. J Neurosci 20:8493-8503.

Bevers EM, Comfurius P, Dekkers DW, Zwaal RF (1999) Lipid translocation across the plasma membrane of mammalian cells. Biochim Biophys Acta 1439:317-330.

Bielefeldt K, Rotter JL, Jackson MB (1992) Three potassium channels in rat posterior pituitary nerve terminals. J Physiol (Lond) 458:41-67.

Brenner R, Jegla TJ, Wickenden A, Liu Y, Aldrich RW (2000) Cloning and functional characterization of novel large conductance calcium-activated potassium channel beta subunits, hKCNMB3 and hKCNMB4. J Biol Chem 275:6453-6461.

Chang CP, Dworetzky SI, Wang J, Goldstein ME (1997a) Differential expression of the alpha and beta subunits of the large-conductance calciumactivated potassium channel: implication for channel diversity. Brain Res Mol Brain Res 45:33-40.

Chavis P, Ango F, Michel JM, Bockaert J, Fagni L (1998) Modulation of big $\mathrm{K}+$ channel activity by ryanodine receptors and L-type $\mathrm{Ca} 2+$ channels in neurons. Eur J Neurosci 10:2322-2327.

Chavko M, Nemoto EM, Melick JA (1993) Regional lipid composition in the rat brain. Mol Chem Neuropathol 18:123-131.

Chu B, Vellareddy A, Treistman SN (1995) Ethanol inhibition of recombinant heteromeric NMDA channels in the presence and absence of modulators. J Neurochem 65:140-148.

Chu B, Dopico AM, Lemos JR, Treistman SN (1998) Ethanol potentiation of calcium-activated potassium channels reconstituted into planar lipid bilayers. Mol Pharmacol 54:397-406.

Clarke AL, Petrou S, Walsh Jr JV, Singer JJ (2002) Modulation of BK(Ca) channel activity by fatty acids: structural requirements and mechanism of action. Am J Physiol Cell Physiol 283:C1441-C1453.

Coetzee WA, Amarillo Y, Chiu J, Chow A, Lau D, McCormack T, Moreno H, Nadal MS, Ozaita A, Pountney D, Saganich M, Vega-Saenz de Miera E, Rudy B (1999) Molecular diversity of K+ channels. Ann NY Acad Sci 868:233-285.

Crews FT, Morrow AL, Criswell H, Breese G (1996) Effects of ethanol on ion channels. Int Rev Neurobiol 39:283-367.

Crowley JJ, Treistman SN, Dopico AM (2003) Cholesterol antagonizes ethanol potentiation of human brain BKCa channels reconstituted into phospholipid bilayers. Mol Pharmacol 64:365-372.

Davies AG, Pierce-Shimomura JT, Kim H, VanHoven MK, Thiele TR, Bonci A, Bargmann CI, McIntire SL (2003) A central role of the BK potassium channel in behavioral responses to ethanol in C. elegans. Cell 115:655-666.

Dopico AM, Lemos JR, Treistman SN (1996) Ethanol increases the activity of large conductance, $\mathrm{Ca}(2+)$-activated $\mathrm{K}+$ channels in isolated neurohypophysial terminals. Mol Pharmacol 49:40-48.

Dopico AM, Widmer H, Wang G, Lemos JR, Treistman SN (1999) Rat supraoptic magnocellular neurones show distinct large conductance, $\mathrm{Ca} 2+$-activated $\mathrm{K}+$ channel subtypes in cell bodies versus nerve endings. J Physiol (Lond) 519:101-114.

Edgerton JR, Reinhart PH (2003) Distinct contributions of small and large conductance $\mathrm{Ca} 2+$-activated $\mathrm{K}+$ channels to rat Purkinje neuron function. J Physiol (Lond) 548:53-69.

Faber ES, Sah P (2002) Physiological role of calcium-activated potassium currents in the rat lateral amygdala. J Neurosci 22:1618-1628.

Golding NL, Jung HY, Mickus T, Spruston N (1999) Dendritic calcium spike initiation and repolarization are controlled by distinct potassium channel subtypes in CA1 pyramidal neurons. J Neurosci 19:8789-8798.

Gribkoff VK, Starrett JEJ, Dworetzky SI (1997) The pharmacology and molecular biology of large-conductance calcium-activated (BK) potassium channels. Adv Pharmacol 37:319-348.

Gruss M, Henrich M, Konig P, Hempelmann G, Vogel W, Scholz A (2001) Ethanol reduces excitability in a subgroup of primary sensory neurons by activation of BK(Ca) channels Eur J Neurosci 14:1246-1256.

Haberstock-Debic H, Wein M, Barrot M, Colago EE, Rahman Z, Neve RL, Pickel VM, Nestler EJ, von Zastrow M, Svingos AL (2003) Morphine acutely regulates opioid receptor trafficking selectively in dendrites of nucleus accumbens neurons. J Neurosci 23:4324-4332.

Hamill OP, Marty A, Neher E, Sakmann B, Sigworth FJ (1981) Improved patch-clamp techniques for high-resolution current recording from cells and cell-free membrane patches. Pflügers Arch 391:85-100.

Hicks GA, Marrion NV (1998) Ca2+-dependent inactivation of large con- 
ductance $\mathrm{Ca} 2+$-activated $\mathrm{K}+(\mathrm{BK})$ channels in rat hippocampal neurones produced by pore block from an associated particle. J Physiol (Lond) 508:721-734.

Hoffman DA, Magee JC, Colbert CM, Johnston D (1997) K+ channel regulation of signal propagation in dendrites of hippocampal pyramidal neurons. Nature 387:869-875.

Isaacson JS, Murphy GJ (2001) Glutamate-mediated extrasynaptic inhibition: direct coupling of NMDA receptors to $\mathrm{Ca}(2+)$-activated $\mathrm{K}+$ channels. Neuron 31:1027-1034.

Jakab M, Weiger TM, Hermann A (1997) Ethanol activates maxi Ca2+activated $\mathrm{K}+$ channels of clonal pituitary (GH3) cells. J Membr Biol 157:237-245.

Kaczorowski GJ, Knaus HG, Leonard RJ, McManus OB, Garcia ML (1996) High-conductance calcium-activated potassium channels; structure, pharmacology, and function. J Bioenerg Biomembr 28:255-267.

Kalluri HS, Ticku MK (1999) Effect of ethanol on phosphorylation of the NMDAR2B subunit in mouse cortical neurons. Brain Res Mol Brain Res 68:159-168.

Kang J, Huguenard JR, Prince DA (1996) Development of BK channels in neocortical pyramidal neurons. J Neurophysiol 76:188-198.

Knaus HG, Schwarzer C, Koch RO, Eberhart A, Kaczorowski GJ, Glossmann H, Wunder F, Pongs O, Garcia ML, Sperk G (1996) Distribution of high-conductance $\mathrm{Ca}^{2+}$-activated $\mathrm{K}^{+}$channels in rat brain: targeting to axons and nerve terminals. J Neurosci 16:955-963.

Knott TK, Dopico AM, Dayanithi G, Lemos J, Treistman SN (2002) Integrated channel plasticity contributes to alcohol tolerance in neurohypophysial terminals Mol Pharmacol 62:135-142.

Koltchine V, Anantharam V, Wilson A, Bayley H, Treistman SN (1993) Homomeric assemblies of NMDAR1 splice variants are sensitive to ethanol. Neurosci Lett 152:13-16.

Lippiat JD, Standen NB, Harrow ID, Phillips SC, Davies NW (2003) Properties of $\mathrm{BK}(\mathrm{Ca})$ channels formed by bicistronic expression of hSloalpha and beta1-4 subunits in HEK293 cells. J Membr Biol 192:141-148.

London E (2002) Insights into lipid raft structure and formation from experiments in model membranes. Curr Opin Struct Biol 12:480-486.

Malenka RC, Nicoll RA (1993) NMDA-receptor-dependent synaptic plasticity: multiple forms and mechanisms. Trends Neurosci 16:521-527.

Marrion NV, Tavalin SJ (1998) Selective activation of Ca2+-activated K+ channels by co-localized Ca2 + channels in hippocampal neurons. Nature 395:900-905.

Martin ED, Araque A, Buno W (2001) Synaptic regulation of the slow $\mathrm{Ca} 2+$-activated $\mathrm{K}+$ current in hippocampal CA1 pyramidal neurons: implication in epileptogenesis. J Neurophysiol 86:2878-2886.

Martin G, Siggins GR (2002) Electrophysiological evidence for expression of glycine receptors in freshly isolated neurons from nucleus accumbens. J Pharmacol Exp Ther 302:1135-1145.

Martina M, Vida I, Jonas P (2000) Distal initiation and active propagation of action potentials in interneuron dendrites. Science 287:295-300.

McManus OB (1991) Calcium-activated potassium channels: regulation by calcium. J Bioenerg Biomembr 23:537-560.

Meera P, Wallner M, Toro L (2000) A neuronal beta subunit (KCNMB4) makes the large conductance, voltage- and $\mathrm{Ca} 2+$-activated $\mathrm{K}+$ channel resistant to charybdotoxin and iberiotoxin. Proc Natl Acad Sci USA 97:5562-5567.
Meredith GE (1999) The synaptic framework for chemical signaling in nucleus accumbens. Ann NY Acad Sci 877:140-156.

Mickus T, Jung H, Spruston N (1999) Properties of slow, cumulative sodium channel inactivation in rat hippocampal CA1 pyramidal neurons. Biophys J 76:846-860.

Mihic SJ, Ye Q, Wick MJ, Koltchine VV, Krasowski MD, Finn SE, Mascia MP, Valenzuela CF, Hanson KK, Greenblatt EP, Harris RA, Harrison NL (1997) Sites of alcohol and volatile anaesthetic action on GABA(A) and glycine receptors. Nature 389:385-389.

Moczydlowski E, Alvarez O, Vergara C, Latorre R (1985) Effect of phospholipid surface charge on the conductance and gating of a $\mathrm{Ca} 2+$-activated $\mathrm{K}+$ channel in planar lipid bilayers. J Membr Biol 83:273-282.

Nie Z, Madamba S, Siggins GR (1994) Ethanol inhibits glutamatergic neurotransmission in nucleus accumbens neurons by multiple mechanisms. J Pharmacol Exp Ther 271:1566-1573.

Nimigean CM, Magleby KL (1999) The beta subunit increases the Ca2+ sensitivity of large conductance $\mathrm{Ca} 2+$-activated potassium channels by retaining the gating in the bursting states. J Gen Physiol 113:425-440.

Pedarzani P, Kulik A, Muller M, Ballanyi K, Stocker M (2000) Molecular determinants of $\mathrm{Ca} 2+$-dependent $\mathrm{K}+$ channel function in rat dorsal vagal neurones. J Physiol (Lond) 527:283-290.

Peoples RW, Stewart RR (2000) Alcohols inhibit N-methyl-D-aspartate receptors via a site exposed to the extracellular environment. Neuropharmacology 39:1681-1691.

Reyes A (2001) Influence of dendritic conductances on the input-output properties of neurons. Annu Rev Neurosci 24:653-675.

Shao LR, Halvorsrud R, Borg-Graham L, Storm JF (1999) The role of BKtype $\mathrm{Ca} 2+$-dependent $\mathrm{K}+$ channels in spike broadening during repetitive firing in rat hippocampal pyramidal cells. J Physiol (Lond) 521:135-146.

Trujillo KA, Akil H (1995) Excitatory amino acids and drugs of abuse: a role for $N$-methyl-D-aspartate receptors in drug tolerance, sensitization and physical dependence. Drug Alcohol Depend 38:139-154.

Vergara C, Latorre R, Marrion NV, Adelman JP (1998) Calcium-activated potassium channels. Curr Opin Neurobiol 8:321-329.

Walters FS, Covarrubias M, Ellingson JS (2000) Potent inhibition of the aortic smooth muscle maxi-K channel by clinical doses of ethanol. Am J Physiol Cell Physiol 279:C1107-C1115.

Weiger TM, Holmqvist MH, Levitan IB, Clark FT, Sprague S, Huang WJ, Ge P, Wang C, Lawson D, Jurman ME, Glucksmann MA, Silos-Santiago I, DiStefano PS, Curtis R (2000) A novel nervous system $\beta$ subunit that downregulates human large conductance calcium-dependent potassium channels. J Neurosci 20:3563-3570.

Welti R, Glaser M (1994) Lipid domains in model and biological membranes. Chem Phys Lipids 73:121-137.

Widmer H, Lemos JR, Treistman SN (1998) Ethanol reduces the duration of single evoked spikes by a selective inhibition of voltage-gated calcium currents in acutely dissociated supraoptic neurons of the rat. J Neuroendocrinol 10:399-406.

Williams SR, Stuart GJ (2000) Action potential backpropagation and somato-dendritic distribution of ion channels in thalamocortical neurons. J Neurosci 20:1307-1317.

Zagotta WN (2001) Structure that opens the gate and opens the door. Neuron 29:547-548. 